\title{
Evaluation of Opportunities to Reduce the Carbon Footprint of Fresh and Canned Pineapple Processing in Central Thailand
}

\author{
Phairat Usubharatana, Harnpon Phungrassami* \\ Excellence Centre of Eco-Energy (ECEE), Department of Chemical Engineering, Faculty of Engineering, \\ Thammasat University, Pathumthani 12120, Thailand
}

Received: 31 January 2017

Accepted: 12 March 2017

\begin{abstract}
This study was proposed to estimate the carbon footprint $(\mathrm{CF})$ and analyze the environmental hotspot of pineapple cultivation and canned pineapple production, and offer opportunities to reduce its CF. The studied cultivation area covered 158 ha, divided into small, medium-sized, and large farms. Input data including organic fertilizer, synthetic fertilizer, herbicides, and fossil fuels were included in the cultivation process, while fossil fuels, chemicals, packaging, and wastewater treatment were included in the production process. The results revealed that the $\mathrm{CF}$ of pineapple cultivation was $172 \mathrm{~g} \mathrm{CO}_{2} \mathrm{eq} / \mathrm{kg}$ of fresh pineapple, with the main contribution being fertilization usage, which accounted for $58-79 \%$ (depending on the size of the farm). In addition, canned pineapple had a $\mathrm{CF}$ of $738 \mathrm{~g} \mathrm{CO}_{2}$ eq/can (30 oz.), with the main contribution being packaging production at $42 \%$. Moreover, feasible ways to reduce greenhouse gas (GHG) emissions - such as replacing fossil fuels with biomass, using biogas from wastewater treatment as a substitute for fuels used in the factory, humidity reduction in fossil fuels used in steam production, and introducing packaging from recycled cans - were all taken into account in this study.
\end{abstract}

Keywords: agriculture, carbon footprint, global warming, life cycle assessment, pineapple

\section{Introduction}

Starting around 2010, the demand for non-food agricultural products increased in contrast to decreasing output. As a result, concerns arose about food security and the ability to sustainably increase agricultural productivity [1]. However, the more productivity is improved, the greater adverse impact it will have on the environment. Waste

*e-mail: pharnpon@engr.tu.ac.th resulting from agricultural operations has to be handled responsibly by those in charge of managing agricultural residue and by-products, including nutrient problems due to runoff from cultivated lands, the possible contamination of groundwater from crop production [2], and air pollution such as greenhouse gas (GHG) emissions. Edenhofer et al. [3] revealed that $25 \%$ of total global emissions of $\mathrm{CO}_{2}$ come from agriculture, forestry, and other land uses, including land-based $\mathrm{CO}_{2}$ emissions from forest fires, peat fires, and peat decay. In Thailand, as an agricultural country listed in Non-Annex I, GHG emissions amounted 
to approximately 350.7 million tons of $\mathrm{CO}_{2}$ in 2012, $16 \%$ of which came from agriculture and land use change [4]. Hence, agriculture is the vital and inevitable sector that should be addressed in order to implement a truly effective plan or roadmap for sustainably reducing GHG emissions in Thailand. Furthermore, Thailand has shown its consent to the $21^{\text {st }}$ Conference of Parties Agreement (COP21) to maintain the level of climate change at a safe level of around 1.5 or $2^{\circ} \mathrm{C}$, which consequently has brought up an attempt to lessen national GHG emissions.

To effectively reduce GHG emissions, an assessment tool is essential for benchmarking the practical plan and the management of GHG. Effective mitigation of climate change cannot be executed without the understanding of net GHG emissions involving activities, materials, and energy used from the agricultural sector [5]. Therefore, life cycle assessment (LCA) can be one of the best methodologies for the environmental consequences of agri-food systems [6]. One of the impact categories that has been the most widely studied using LCA is global warming potential and International Standard ISO14067:2013, which is the universally accepted standard for calculating the carbon footprint $(\mathrm{CF})$ of products or activities [7], including agricultural intensification.

$\mathrm{CF}$ is a measure used to assess the amount of anthropogenic GHG emissions expressed in an amount of $\mathrm{CO}_{2}$ equivalent $\left(\mathrm{CO}_{2} \mathrm{eq}\right)$. As agriculture is one of the contributors to anthropogenic emissions of GHGs, the quantification of agricultural practices is crucial for identification of more sustainable practices [8]. Several studies have evaluated and assessed a variety of agricultural crops and products by applying CF methodology, such as organic blueberry production in Chile [9], strawberry paste production [10], and winter lettuce production in the U.S. [11]. However, there is little current research information about GHG emissions in the pineapple sector, especially pineapple processing. Ingwersen [12] assessed the LCA of fresh pineapples from Costa Rica and retail shelves in the U.S. Another study focused on the CF of a fresh pineapple producer in Ghana and an importer in the Netherlands [13]. To date, only one study has involved the $\mathrm{CF}$ of pineapple processing, which was the CF of fresh pineapple and pineapple jam produced in Mauritius and sold to Europe [14]. This study then focused on environmental impact from the aspect of global warming potential - not only in pineapple cultivation but also in canned pineapple processing.

Pineapple is an important economic fruit of Thailand, with the fourth-largest production capacity in the world, estimated at 2.2 million tons in 2013 [15]. However, Thailand is number one for canned pineapple export with the capacity in total of 600,000 tons in the same year, while global capacity at the time was 2.1 million tons [15].

As mentioned above, pineapple products are mainly produced by original equipment manufacturers (OEM), which are facing ever-increasing pressure from set environmental measures. This study proposed an assessment CF for pineapple cultivation and canned pineapple processing to identify the hot spots of GHG emissions in the product system boundary, including cultivation, harvesting, and transportation. This paper aims to establish benchmarks for both domestic and international pineapple processing industries and to suggest opportunities or measures to reduce $\mathrm{CF}$. Complying with the national GHG emissions reduction strategy, by the national pineapple strategic planner, is the main contribution of this present research.

\section{Material and Methods}

To determine the $\mathrm{CF}$ of chosen products along their entire life cycle and focus on GHG emissions, the methodology used in this study follows ISO14067:2013 [16]. In case ISO14067 does not afford clear guidance, the National Guidance on Carbon Footprint Calculation for Products Ver. 5, Thailand, was chosen in order to be consistent with the context of the country. The national guideline has been developed by a Thai carbon footprint technical committee, with the Thailand greenhouse gas management organization (TGO) as scheme owner. To comply with the conventional approach, the methodology for this study was presented following the LCA step according to ISO14040:2006 [17] and ISO14044:2006 [18]. The LCA methodology consists of four steps, including 1) goal and scope definition, 2) life cycle inventory, 3) life cycle impact assessment, and 4) interpretation.

\section{Goal and Scope Definition}

\section{Goal and Target Audience}

The main research goal for the measurement of CF was to establish the impact on global warming resulting from fresh pineapple and pineapple production and processing in the central area of Thailand. Additional objectives were to identify hot spots of CF for this industry and apply the opportunities to reduce GHG emissions along with the product system boundary. The farm-to-gate system boundary was studied, including pineapple cultivation, transportation of fresh pineapple to the factory, and canned pineapple processing.

The target audience should be comprised of interested stockholders such as consumers, producers, researchers, or even highly educated farmers, as well as all concerned with environmental issues related to agricultural cultivation and food processing to improve environmental performance, sustainability, and awareness. Moreover, the results might be used for the national pineapple strategic planner to comply with the national GHG emissions reduction strategy in the future. These results also increase the value added for producers, which are mostly the original equipment manufacturers (OEM), in order to have more success in the competitive international market. 


\section{Functional Unit and System Boundary}

According to ISO14040:2006 [17], a functional unit is the quantified performance of a product system to be used as a reference unit in an LCA study. The functional unit for agricultural products can be set as the physical properties (mass-based or volume-based) of the selected product, such as $1 \mathrm{~kg}$ of harvested blueberries [9]. However, some studies have set the functional unit as a unit of food, such as one serving of pineapple at a retailer [12]. The most commonly used functional unit for food products is based on mass [19]. Therefore, the functional unit in this study was set as $1 \mathrm{~kg}$ of fresh pineapple and one canned pineapple with a net weight of $30 \mathrm{oz}$.

The system boundary of the study was set from the cradle-to-farm gate for one $\mathrm{kg}$ of fresh pineapple and the cradle-to-factory gate for one canned pineapple, as illustrated by Fig 1. Pineapple cultivation and harvesting were considered from the production of inputs (fertilizer, insecticide, herbicide, fuels) and outputs (emission to air from fuel combustion and $\mathrm{N}_{2} \mathrm{O}$ from $\mathrm{N}$-fertilizer). Furthermore, the nursery stage had to be excluded because the most common method of propagation is planting by ratoon. Direct land use change (dLUC) was also excluded due to a lack of information dating back to 20 years before cultivation. The mode of transportation for fresh pineapples to a factory was also counted in the $\mathrm{CF}$ assessment. Canned pineapple processing included the following: electricity, fuel for steam production, water used in the process and product, sugar as an ingredient, and the tin can for packaging.

\section{Inventory and Data Collection}

\section{Pineapple Cultivation}

The cultivar in this study is Smooth Cayenne, which is the main species grown for canned pineapple factories. The main regions for plantations are Prachuap Khiri Khan Province, Phetchaburi Province, and Ratchaburi Province, as well as Kanchanaburi Province (central region) and Chonburi Province, Chachoengsao Province, and Prachinburi Province (eastern region). The cultivation process leading to harvest takes approximately 12-18 months. For the period of 2010-11, data was collected from 25 participating pineapple planting areas located in the central region of Thailand. Primary data was derived from farmers selling pineapples to a factory using designed questionnaires and interviews, which were gathered with help from the factories with contractual agreements with those farmers. Collected data included general information about their plantations such as area and yield, use of fertilizers and insecticides, or fuel consumption. The studied farms covered a total area of $158 \mathrm{ha}$; the farms ranged from small- to large-scale with ranking associated to the area of plantation. The size of the farms was classified according to the size of the area used in plantation. To illustrate, a planting area not over 1.44 ha was recognized as a small farm, 1.6-3.2 ha was a medium-sized farm, and a big farm had to have an area of at least 3.2 ha for the plantation [20]. The studied areas account for $0.2 \%$ of all cultivation areas in the central part of Thailand and $0.16 \%$ in the whole country as of 2010 . This reflects the fact that most cultivation areas are located in the central part of the country. The cultivation process is comprised of two steps: soil preparation and cultivation. In the areas used previously for plantation, pineapple waste remaining in the soil is either collected for use as animal feed (pineapple hay) or left to dry out for standing burn. However, this process was not taken into consideration for this study due to a lack of information about the actual amount of pineapple waste in the soil. Normally, one pineapple plant can last 3-4 years before subsequently being replaced. The soil must be well tilled and layered prior to planting. Then it is nourished using organic fertilizer (chicken manure) and chemical fertilizers such as NPK complex fertilizer (15-15-15), etc. In the planting process, 4,000-10,000 pineapple plants are grown per 0.16 ha. In addition, the farmers choose chicken manure as the main fertilizer since the land is mostly sandy loam and they use various chemical fertilizers such as ammonium sulfate fertilizer (21-0-0), urea fertilizer (46-0-0), NPK complex fertilizer (15-15-15), or potash fertilizer (0-0-60; including diuron,

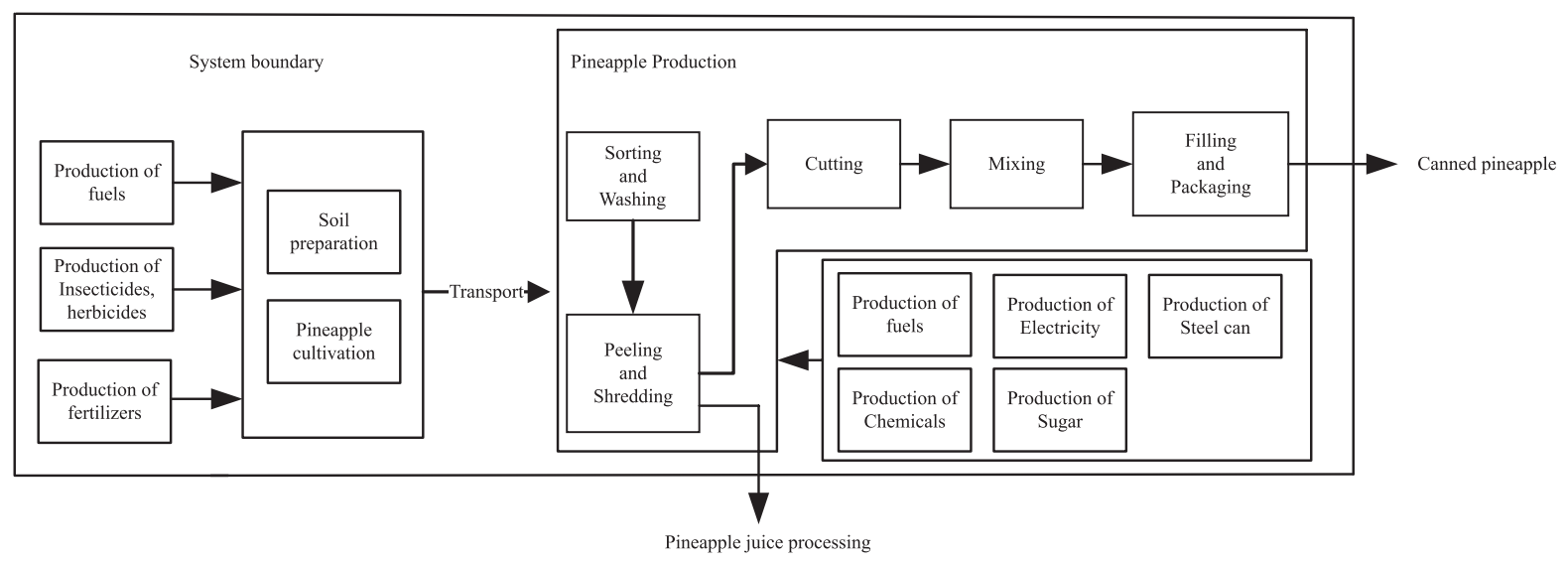

Fig. 1. System boundary. 
bromacil, ametryne, or diazinon) for weed and pest control.

\section{Canned Pineapple Production}

The participating factory conducting pineapple processing operations is located in central Thailand. The planting farms are within a radius of $10-270 \mathrm{~km}$. The canned pineapple production process (Fig. 1) starts from cleaning, followed by sorting, peeling, core removing, eye cutting, and trimming. Selected pineapples are taken for canned pineapple production, while some are used for pineapple juice (outside the system boundary) and the rest are sold for animal feed. In detail, pineapples are washed using water jets to clean out dirt or ants prior to the production process. Then washed pineapples are conveyed to a big sorting machine. Big pineapples are sorted for canned pineapple production while smaller ones are sorted to make pineapple juice. Peeling, coring, and eye removal are in the same single step done by humans, followed by trimming and cutting into slices using a machine. Water is required throughout the process for cleansing purposes. The last process involves adding sugar and canning. Obviously, the main inputs are electricity, water and steam consumption, other additives such as sugar, as well as tin cans for packaging. GHG emissions arising from the production of capital goods, however, have been excluded in our assessment.

\section{Impact Assessment and Calculation Method}

To assess global warming potential (GWP), CF evaluation in compliance with ISO14067:2013 [16] is applied in this study together with the National Guidance on Carbon Footprint Calculation. CF is a tool used to estimate the amount of GHG emissions throughout the life cycle of a product. GWP is expressed as $\mathrm{CO}_{2}$-equivalents, or $\mathrm{CO}_{2}$ eq, and is a single impact category assessment. The GWP of $\mathrm{CO}_{2}, \mathrm{CH}_{4}$, and $\mathrm{N}_{2} \mathrm{O}$, for example, are expressed as 1,25 , and 298 times $\mathrm{CO}_{2}$, respectively, at a time interval of 100 years [21]. The said figures are the sum amount from all sources of emissions, including direct and indirect GHG emissions involving all relevant activities in the system boundary of a selected product.

Direct GHG emissions are caused by fuel combustion and $\mathrm{N}_{2} \mathrm{O}$ from $\mathrm{N}$-fertilizer, as well as $\mathrm{CO}_{2}$ from using urea fertilizer. The three main gases released from combustion are $\mathrm{CO}_{2}, \mathrm{CH}_{4}$, and $\mathrm{N}_{2} \mathrm{O}$, which can be calculated by IPCC, while the use of synthetic and organic nitrogen fertilizer triggering $\mathrm{N}_{2} \mathrm{O}$ results in $\mathrm{N}_{2} \mathrm{O}$ emission factor $1 \%$ of $\mathrm{N}$ released as $\mathrm{N}_{2} \mathrm{O}$ [20]. The percentages of nitrogen $(\mathrm{N})$, phosphorous $(\mathrm{P})$, and potassium $(\mathrm{K})$ in organic fertilizer (chicken manure) are $2.06 \%, 0.25 \%$, and $1.24 \%$, respectively [22].

Indirect GHG emissions are released from the production of inputs required in the cultivation process such as fertilizer production. This includes chicken manure production, fuel production, etc. This also includes inputs used in pineapple processing such as electricity production, fuel production, and chemical production, among others. Once the activity data has been identified, the proposed methodology can be applied to calculate the CF of each activity. A general expression for the CF calculation for indirect GHG emissions (Eq. 1) can be expressed as follows:

$$
C O_{2} e q=\sum_{i=1}^{i=n} A_{i} \times E F_{i}
$$

...where the indirect $\mathrm{CF}$ is derived by applying each activity data $\left(\mathrm{A}_{\mathrm{i}}\right)$ multiplied by an emission factor $\left(\mathrm{EF}_{\mathrm{i}}\right)$ of compliance with that activity data. Total CF of a product is a summation of direct and indirect GHG emissions. Background data, such as for fertilizer production, herbicide and insecticide production, and coal production was obtained from the Ecoinvent 2.0 database [23]. Additionally, some background data was provided by the Thailand National LCI database [24], which is available at the TGO website (www.tgo.or.th), such as electricity production, diesel gasoline and LPG production, sugar production, and tin can production. Since data obtained from the Thailand National LCI database means that all activities took place in Thailand, the acquired data offers information closer to reality than secondary data sourced from abroad. Water production was the primary data obtained from within factory processing. Such background data was calculated and expressed as EF of each activity data.

\section{Results and Discussion}

In this section, the life cycle inventory of fresh pineapple and canned pineapple processing is given in section 3.1. The CF of these products is presented in section 3.2, while the interpretation and opportunities to reduce GHG emissions are expressed in section 3.3.

\section{Life Cycle Inventory Results}

\section{Fresh Pineapple Inventory}

According to the questionnaire answered by 25 participating farmers, their planting areas covered approximately 160 ha and contributed to output at around $37,900 \mathrm{~kg} / \mathrm{ha}$ on average, as shown in Table 1 .

The farm size distribution in the study was $4 \%$ from farms $<1.44$ ha (small farm size), $32 \%$ from farms between 1.6 and 3.2 ha (medium farm size), and $64 \%>3.2-$ 16 ha (large farm size). For soil preparation, small farms used only organic fertilizer made from chicken manure, while medium-sized and large farms used both chicken manure and chemical fertilizer. When considering only $\mathrm{N}$ fertilizer in particular (chicken manure and chemical fertilizer included), as shown in Table 2, it was found that small farms used more than $386 \mathrm{~kg} /$ ha of $\mathrm{N}$ fertilizer, while medium-sized and large farms used $\mathrm{N}$ fertilizer in a relatively similar portion at $114 \mathrm{~kg} / \mathrm{ha}$ and $118 \mathrm{~kg} / \mathrm{ha}$, 
Table 1. Summary of data for fresh pineapple cultivation.

\begin{tabular}{|c|c|c|c|c|c|}
\hline & & & \multicolumn{3}{|c|}{ Farm size } \\
\hline Category & Item & Unit & $<1.44$ ha & $1.6-3.2 \mathrm{ha}$ & $>3.2$ ha \\
\hline \multirow{2}{*}{ Product } & Average yield & $\mathrm{kg} / \mathrm{ha} /$ harvest & 31,250 & 36,163 & 38,238 \\
\hline & Average fresh pineapple weight & $\mathrm{kg} /$ pineapple & 0.80 & 0.81 & 0.89 \\
\hline \multirow{5}{*}{ Soil preparation } & Chicken manure fertilizer & $\mathrm{kg} / \mathrm{ha}$ & 18,750 & 5,356 & 4,994 \\
\hline & N-fertilizer & $\mathrm{kg} / \mathrm{ha}$ & 0 & 3.38 & 5.00 \\
\hline & P-fertilizer & $\mathrm{kg} / \mathrm{ha}$ & 0 & 3.38 & 5.00 \\
\hline & K-fertilizer & $\mathrm{kg} / \mathrm{ha}$ & 0 & 3.38 & 5.00 \\
\hline & Diesel & $\mathrm{L} / \mathrm{ha}$ & 656.25 & 818.13 & 645.63 \\
\hline \multirow{11}{*}{$\begin{array}{l}\text { Cultivation and } \\
\text { harvesting }\end{array}$} & Chicken manure fertilizer & $\mathrm{kg} / \mathrm{ha}$ & 18,750 & 16,519 & 8,875 \\
\hline & $\mathrm{N}$-fertilizer & $\mathrm{kg} / \mathrm{ha}$ & 19.38 & 44.50 & 70.31 \\
\hline & P-fertilizer & $\mathrm{kg} / \mathrm{ha}$ & 19.38 & 10.94 & 21.56 \\
\hline & K-fertilizer & $\mathrm{kg} / \mathrm{ha}$ & 19.38 & 46.63 & 102.94 \\
\hline & Ethephon & $\mathrm{kg} / \mathrm{ha}$ & 0 & 1.13 & 1.50 \\
\hline & Calcium carbide & $\mathrm{kg} / \mathrm{ha}$ & 0 & 0.69 & 5.00 \\
\hline & Herbicide & $\mathrm{kg} / \mathrm{ha}$ & 9.38 & 9.38 & 8.00 \\
\hline & Insecticide & $\mathrm{kg} / \mathrm{ha}$ & 3.13 & 0.56 & 0.88 \\
\hline & Diesel & $\mathrm{L} / \mathrm{ha}$ & 0 & 37.94 & 107.25 \\
\hline & Gasoline & $\mathrm{L} / \mathrm{ha}$ & 0 & 0 & 82.81 \\
\hline & LPG & $\mathrm{kg} / \mathrm{ha}$ & 0 & 0 & 33.31 \\
\hline
\end{tabular}

respectively. During the cultivation and harvesting period, small farms used more chicken manure than mediumsized and large farms did. In terms of N-fertilizer, small farms used more than $406 \mathrm{~kg} / \mathrm{ha}$, while medium-sized and large farms used around $385 \mathrm{~kg} / \mathrm{ha}$ and $253 \mathrm{~kg} /$ ha of this fertilizer, respectively. It is notable that large farms tended to use more chemical fertilizer than organic fertilizer, whereas small farms used more fertilizer per one $\mathrm{kg}$ of pineapple than the other farm sizes did. To force pineapples to induce flowering, farmers would use calcium carbide to react with water and release acetylene and ethephon $48 \%$ (2-chloroethyl phosphonic acid). Once it dissolved it released ethylene. Both gases are able to force pineapple plants into the flowering stage. Large farms were more likely to use chemicals for this purpose than small and medium-sized farms. Similarly, large farms also consumed more fuel than small and medium-sized farms.

\section{Canned Pineapple Processing Inventory}

Certain inventory data is commercially sensitive. Therefore, the data illustrated in this section contains limited information. Pertaining to pineapple transportation from the farms the information used to assess CF was based on loading capacity, distance, and types of vehicles.

Table 2. Amount of organic and synthetic fertilizers used for each farm size.

\begin{tabular}{|c|c|c|c|c|c|c|c|c|c|c|}
\hline & & \multicolumn{3}{|c|}{ Small farm } & \multicolumn{3}{c|}{ Medium-sized farm } & \multicolumn{3}{c|}{ Large farm } \\
\hline & Unit & $\mathrm{N}$ & $\mathrm{P}$ & $\mathrm{K}$ & $\mathrm{N}$ & $\mathrm{P}$ & $\mathrm{K}$ & $\mathrm{N}$ & $\mathrm{P}$ & $\mathrm{K}$ \\
\hline $\begin{array}{c}\text { Soil } \\
\text { Preparation }\end{array}$ & $\mathrm{kg} / \mathrm{ha}$ & 386.25 & 46.88 & 232.50 & 113.69 & 16.75 & 69.75 & 118.19 & 21.63 & 71.06 \\
\hline $\begin{array}{c}\text { Cultivation and } \\
\text { harvesting }\end{array}$ & $\mathrm{kg} / \mathrm{ha}$ & 405.63 & 66.25 & 251.88 & 384.75 & 52.25 & 251.50 & 253.19 & 43.75 & 213.00 \\
\hline Total & $\mathrm{kg} / \mathrm{ha}$ & 791.88 & 113.13 & 484.38 & 498.44 & 69.00 & 321.25 & 371.38 & 65.38 & 284.06 \\
\hline Total & $\begin{array}{c}\mathrm{kg} / \mathrm{kg} \text { fresh } \\
\text { pineapple }\end{array}$ & 0.0253 & 0.0036 & 0.0155 & 0.0138 & 0.0019 & 0.0089 & 0.0097 & 0.0017 & 0.0074 \\
\hline
\end{tabular}


Table 3. Emission factor of truck transportation.

\begin{tabular}{|c|c|c|}
\hline Vehicle type & Full load $(\mathrm{tkm})$ & $0 \%$ loading $(\mathrm{km})$ \\
\hline 18-wheel truck & 0.0447 & 0.8163 \\
\hline 4-wheel truck & 0.1402 & 0.3111 \\
\hline
\end{tabular}

Source: [24]

According to the information, $95 \%$ of pineapples fed to processing in the factory were delivered using 18-wheeled trucks, while $5 \%$ were loaded on 4 -wheeled trucks. The factory would dispatch trucks to pick up $95 \%$ of their pineapples right at the farms that they already had contractual agreements with, while the remaining 5\% were bought from farmers in front of the factory. These pineapples were cultivated in three provinces, which were the province in which the factory was located and two others nearby. $75 \%$ came from the same province as the factory, while the rest came from nearby provinces. To calculate $\mathrm{CF}$, distance and types of vehicles were taken into account. Table 3 presents emission factors in terms of truck transportation under the assumption that the truck was $0 \%$ loaded from the factory to the farm, and then fully loaded on the return trip.

As mentioned earlier, residue or smaller pieces sorted out of canned pineapple production would be taken to produce pineapple juice or sold as animal feed. According to the information provided by the factory, more than 5,633 tons of fresh pineapples are needed per month. After peeling and core removal, 1,183 tons/month were used for canned pineapple production and 3,577 tons/month were used for pineapple juice. Residue and waste amounted to 873 tons/month. The other ingredients such as sugar, citric acid, and anti-foaming agents used in processing contributed to a co-product for which environmental load

Table 4. Summary of primary data for canned pineapple per functional unit $(30 \mathrm{oz}$.).

\begin{tabular}{|c|c|c|}
\hline Item & Unit & \\
\hline Fresh pineapple & $\mathrm{kg}$ & 0.66 \\
\hline Tin can & $\mathrm{kg}$ & 0.10 \\
\hline Cardboard & $\mathrm{kg}$ & 0.02 \\
\hline Sugar & $\mathrm{kg}$ & 0.80 \\
\hline Citric acid and other chemicals & $\mathrm{kg}$ & $<0.001$ \\
\hline Deforming & $\mathrm{kg}$ & $<0.00001$ \\
\hline Electricity & $\mathrm{kWh}$ & 0.02 \\
\hline Coal & $\mathrm{kg}$ & 0.04 \\
\hline Fuel oil & $\mathrm{kg}$ & $<0.01$ \\
\hline Water for steam & $\mathrm{m}^{3}$ & $<0.0003$ \\
\hline Tap water for washing machine & $\mathrm{m}^{3}$ & $<0.0003$ \\
\hline Soft water for processing & $\mathrm{m}^{3}$ & $<0.0006$ \\
\hline
\end{tabular}

needed to be allocated. In this case, percent allocation for this study was then $25 \%$ for canned pineapple since allocation was applied by mass. Inventory data after allocation by mass is expressed in Table 4 .

According to the information in Table 4, the use of electricity and coal to fuel steam production amounted to $0.02 \mathrm{kWh} /$ functional unit and $0.04 \mathrm{~kg}$ coal/functional unit, respectively. Throughout the entire production process, electricity was consumed at $24.7 \mathrm{kWh} /$ ton of product, which was slightly higher than the benchmark $21.40 \mathrm{kWh} /$ ton of product [25]. In terms of water consumption, it was $1.2 \mathrm{~m}^{3} /$ ton, lower than the benchmark $2.1 \mathrm{~m}^{3} /$ ton of product [25]. For estimated emissions from wastewater treatment, the selected factory used a stabilization pond and lagoon. The average BOD loading of the pineapple factory before treatment is usually $3.8 \mathrm{~kg} \mathrm{BOD} /$ ton product [25]. After being treated, the $\mathrm{BOD}_{5}$ was reduced to below $20 \mathrm{mg} / \mathrm{L}$ as the Thailand effluent standard. Based on these $\mathrm{BOD}_{5}$ assumptions, $\mathrm{CH}_{4}$ emission could be estimated from IPCC [21].

\section{Carbon Footprint of Pineapple Cultivation and Processing}

\section{Emissions from Pineapple Cultivation}

The results of average $\mathrm{CF}$ for the 25 pineapple cultivations and percentage contribution of each main inventory is presented in Table 5. Focusing on direct and indirect emissions, about $55 \%$ to $65 \%$ of total GHG emissions from fresh pineapples come from direct emissions. The majority of direct emissions is caused by fuel combustion ( $31 \%$ to $37 \%$ of total GHG emissions), followed by organic fertilizer ( $22 \%$ to $28 \%$ of total GHG emissions) in the case of medium- and large-sized farms. However, for small farms the main factor contribution is caused by direct emissions from organic fertilizer, accounting for $36 \%$, followed by fuel combustion at $18 \%$. Indirect emissions generate $35 \%$ to $45 \%$ contribution, mainly from organic fertilizer production ( $24 \%$ to $41 \%$ of total GHG emissions). Direct and indirect impact proportion of small scale (55:45) was different from medium- (62:38) and large-scale $(65: 35)$ due to the difference of applied fertilizers. The reason for the difference is that the main nutrients ratio $(\mathrm{N}: \mathrm{P}: \mathrm{K})$ in various types of fertilizers are not equal. $\mathrm{N}$ fertilizer played the most important role for greenhouse gas direct impact; therefore, small-scale plantation using less $\mathrm{N}$ contained fertilizer presented the least ratio. Overall, the highest CF stems from the use of all fertilizers, amounting to $58 \%$ to $79 \%$ of both direct and indirect emissions. The second runner up is fuel consumption. The use of chemicals, however, contributed to less than $1 \%$ of total GHG emissions.

Table 6 shows the average CF of three farm sizes per $1 \mathrm{~kg}$ of fresh pineapple. The total average CF of fresh pineapple is $172 \mathrm{~g} \mathrm{CO}_{2}$ eq $/ \mathrm{kg}$ based on output from every farm. Results range from 165 in large farms to $320 \mathrm{~g}$ $\mathrm{CO}_{2} \mathrm{eq} / \mathrm{kg}$ in small farms. However, $88 \%$ of the production 
Table 5. Average carbon footprint and contribution of fresh pineapple production in each farm size.

\begin{tabular}{|c|c|c|c|c|c|c|c|c|c|c|c|c|}
\hline & \multicolumn{6}{|c|}{ Direct emission } & \multicolumn{6}{|c|}{ Indirect emission } \\
\hline & \multicolumn{2}{|c|}{$\mathrm{S}$} & \multicolumn{2}{|c|}{ M } & \multicolumn{2}{|c|}{$\mathrm{L}$} & \multicolumn{2}{|c|}{$\mathrm{S}$} & \multicolumn{2}{|c|}{ M } & \multicolumn{2}{|c|}{$\mathrm{L}$} \\
\hline & & $\%$ & & $\%$ & & $\%$ & & $\%$ & & $\%$ & & $\%$ \\
\hline Organic fertilizer & 115.76 & 36.2 & 58.99 & 28.0 & 35.94 & 21.8 & 131.64 & 41.1 & 66.36 & 31.5 & 39.78 & 24.1 \\
\hline Synthesis fertilizer & 2.90 & 0.9 & 6.20 & 2.9 & 10.49 & 6.4 & 3.33 & 1.0 & 5.68 & 2.7 & 10.12 & 6.1 \\
\hline Herbicide & - & 0.0 & - & 0.0 & - & 0.0 & 2.08 & 0.7 & 1.79 & 0.8 & 1.41 & 0.9 \\
\hline Insecticide & - & 0.0 & - & 0.0 & - & 0.0 & 0.85 & 0.3 & 0.11 & 0.0 & 0.20 & 0.1 \\
\hline Fuel & 57.64 & 18.0 & 65.01 & 30.9 & 60.40 & 36.6 & 5.72 & 1.8 & 6.45 & 3.1 & 6.83 & 4.1 \\
\hline Total & 176.30 & 55.1 & 130.19 & 61.8 & 106.83 & 64.7 & 143.62 & 44.9 & 80.39 & 38.2 & 58.34 & 35.3 \\
\hline
\end{tabular}

unit: $\mathrm{gCO}_{2} \mathrm{eq} / \mathrm{kg}$ fresh pineapple

capacity is from large farms while small farms contribute to $<1 \%$. Therefore, the overall average $\mathrm{CF}$ is relatively similar to the $\mathrm{CF}$ of a large farm. When considering details, the factor of greatest contribution is organic fertilizer at about $45 \%$ to $77 \%$ of the total GHG emissions, followed by fuel use (an average of $20 \%$ to $41 \%$ of total GHG emissions). Meanwhile, the use of chemical fertilizer is responsible for only $2 \%$ to $12 \%$ of total GHG emissions, depending on the size of the farm.

Table 6. Average carbon footprint and contribution of fresh pineapple for each farm size.

\begin{tabular}{|c|c|c|c|c|}
\hline \multirow[b]{2}{*}{ Item } & & \multicolumn{3}{|c|}{ Farm size } \\
\hline & & Small & $\begin{array}{l}\text { Medium- } \\
\text { sized }\end{array}$ & Large \\
\hline \multicolumn{5}{|c|}{ Emissions from Soil Preparation } \\
\hline Chicken manure fertilizer & $\%$ & 38.67 & 14.50 & 16.30 \\
\hline $\mathrm{N}$-fertilizer & $\%$ & 0.00 & 0.35 & 1.94 \\
\hline P-fertilizer & $\%$ & 0.00 & 0.07 & 0.23 \\
\hline K-fertilizer & $\%$ & 0.00 & 0.02 & 0.07 \\
\hline Diesel & $\%$ & 19.80 & 32.43 & 30.85 \\
\hline \multicolumn{5}{|c|}{ Emissions from Cultivation and harvesting } \\
\hline Chicken manure fertilizer & $\%$ & 38.67 & 44.72 & 28.97 \\
\hline $\mathrm{N}$-fertilizer & & 1.55 & 4.67 & 8.89 \\
\hline P-fertilizer & $\%$ & 0.30 & 0.23 & 0.54 \\
\hline K-fertilizer & $\%$ & 0.10 & 0.30 & 0.81 \\
\hline Herbicide & $\%$ & 0.65 & 0.85 & 0.86 \\
\hline Insecticide & $\%$ & 0.27 & 0.05 & 0.12 \\
\hline Diesel & $\%$ & 0.00 & 1.50 & 5.12 \\
\hline Gasoline & $\%$ & 0.00 & 0.00 & 3.60 \\
\hline LPG & $\%$ & 0.00 & 0.00 & 1.12 \\
\hline $\begin{array}{l}\text { Total } \mathrm{gCO}_{2} \mathrm{eq} / \mathrm{kg} \text { fresh } \\
\text { pineapple }\end{array}$ & & 319.92 & 210.58 & 165.18 \\
\hline
\end{tabular}

\section{Emissions from Pineapple Processing}

The CF of canned pineapple is $738 \mathrm{~g} \mathrm{CO}_{2} \mathrm{eq} / \mathrm{fu}$ (30 oz), as shown in Table 7. The most emissions come from packaging (tin can), accounting for $41.6 \%$ of the total $\mathrm{CF}$, followed by fresh pineapple cultivation $(15.9 \%)$. The third contribution is fuel, including the coal and fuel oil used to produce steam for the manufacturing process $(16.6 \%)$. Though sugar is one of the top three contributions, it is still considered the main contributor $(11.6 \%)$. The $\mathrm{CF}$ of fresh pineapple transportation is around $5 \mathrm{~g} \mathrm{CO}_{2} \mathrm{eq} / \mathrm{kg}$, which is also included in the value of $117 \mathrm{~g} \mathrm{CO}_{2} \mathrm{eq} / \mathrm{can}$ of fresh pineapple acquisition, accounting for only $0.4 \%$ of total $\mathrm{CF}$.

Table 7. Carbon footprint and contribution of canned pineapple (30 oz.).

\begin{tabular}{|c|c|c|}
\hline & $\mathrm{gCO}_{2} \mathrm{eq} / \mathrm{fu}$ & $\%$ contribution \\
\hline Fresh pineapple & 117.06 & 15.9 \\
\hline Electricity & 13.45 & 1.8 \\
\hline Coal & 111.98 & 15.2 \\
\hline Fuel oil & 10.83 & 1.5 \\
\hline Water for steam & 0.75 & 0.1 \\
\hline Tap water & 0.18 & 0.0 \\
\hline Soft water for processing & 1.83 & 0.2 \\
\hline Sugar & 85.88 & 11.6 \\
\hline Citric acid and chemicals & 1.86 & 0.3 \\
\hline Deforming & 0.02 & 0.0 \\
\hline Tin can & 307.28 & 41.6 \\
\hline Cardboard & 16.42 & 2.2 \\
\hline Wastewater treatment & 70.30 & 9.5 \\
\hline Total & 737.84 & 100.0 \\
\hline
\end{tabular}




\section{Life Cycle Interpretation}

\section{Cultivation}

To analyze the results from cultivation, three scenarios were classified and compared the $\mathrm{CF}$ results with the base case (CF results from previous section). Scenario 1 is when pineapple residue (leaves) is burnt because, practically, farmers will burn down pineapple plants when the crop season ends to make it easier for the next planting. However, the calculation in the base case does not include pineapple leaves burning due to lack of information. In this scenario, the hypothesis is that farmers always burn down pineapple plants after the crop season ends. According to the report, 1 ha contains approximately 4,340 $\mathrm{kg}$ pineapple leaves [26], with the dry weight of pineapple plants and leaves accounting for $16.67 \%$ [27]. The emission factors of agricultural residue converted to $\mathrm{CH}_{4}$ and $\mathrm{N}_{2} \mathrm{O}$ are 2.7 and $0.07 \mathrm{~g} / \mathrm{kg}$ dry matter burnt [28]. $\mathrm{CO}_{2}$ caused by combustion is not taken into account because the carbon released during burning is reabsorbed during the next growing season [9]. Scenario 2 is when only organic fertilizer is used with no synthetic fertilizer at all. The calculation is done based on the amount of N-P-K fertilizer required by each farm as in the base case. Finally, scenario 3 is considered in accordance with good agricultural practices (GAP) for pineapples, which suggests that N:P:K be used at a ratio of 2:1:3 per $50 \mathrm{~g} /$ plant/season [29]. Fig. 2 shows the CF of fresh pineapple in each scenario compared to the base case.

As shown in Fig. 2 for the base case, the sources of primary data used in this study give a variation of data set. In this case, uncertainty for specific input and results probably occurred. One of the objectives of this study is to show actual information gathered from the agricultural sector, where information is normally different because of farmer's data management limitation. They range from 64 to $378 \mathrm{~g} \mathrm{CO}_{2} \mathrm{eq} / \mathrm{kg}$ of fresh pineapple. Low $\mathrm{CF}$ resulted from less fertilizer use. In scenario 1, the CF result is not much different from that in the base case with less than $1.8 \%$ variance because farmers will burn pineapple residue only when they need to plant new ones. Each plant can give yields of 2-3 times. In scenario 2, the result of $\mathrm{CF}$ for fresh pineapple is the highest, especially if the farms use synthetic fertilizers more than chicken manure. Finally, the CF of scenario 3 is the lowest when compared to the base case, except for $24 \%$ of the farms, which use less fertilizer than suggested. However, variations in information are found to be less than in larger farms.

\section{Comparison of the Results to Other Studies}

The results acquired from other studies were compared and considered only within the same system boundary set as cradle-to-farm gate because the data from post cultivation (farm gate to factory gate or farm gate to disposal) has different uses for each study. Thus, it is not comparable. Table 8 shows the results of other studies in comparison with this study. According to the information, land use change was either not in consideration or did not pose any global warming potential as the area had been used for cultivation for more than 20 years. The average $\mathrm{CF}$ for fresh pineapple in the present study is $0.17 \mathrm{~kg} \mathrm{CO}$ eq $/ \mathrm{kg}$, while it ranges from 0.16 to $0.26 \mathrm{kgCO}_{2} \mathrm{eq} / \mathrm{kg}$ in other literature. However, all studies found that the main contribution is caused by fertilizer application, accounting for $61.6 \%$ [14] and $73 \%$ [13]. In this study, it varies between $58-79 \%$ of total contribution depending on farm size. Regarding $\mathrm{N}_{2} \mathrm{O}$ from fertilizer application, percent contribution is over $40 \%$ [12], while it is around $28-37 \%$ in this study.

\section{Opportunities to Reduce GHG Emissions}

From the aspect of farm management, fertilizer application, particularly $\mathrm{N}$-fertilizer, contributes to high CF. Hence less application can reduce GHG emissions [12]. Life cycle interpretation at cultivation stage reveals

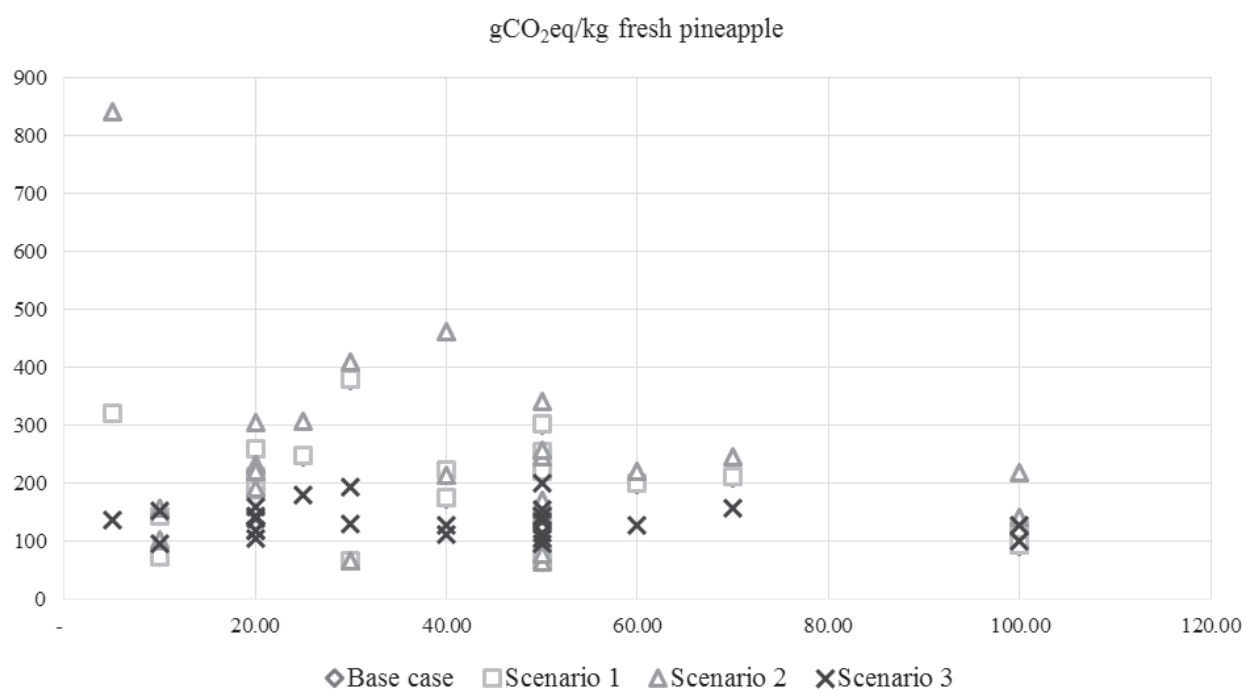

Fig. 2. CF of fresh pineapple in each scenario. 
Table 8. CF of fresh pineapple from other studies.

\begin{tabular}{|c|c|c|c|c|}
\hline & $\begin{array}{c}\text { Ref. } \\
{[14]}\end{array}$ & $\begin{array}{c}\text { Ref. } \\
{[13]}\end{array}$ & $\begin{array}{c}\text { Ref. } \\
{[12]}\end{array}$ & This study \\
\hline Location & Mauritius & Ghana & Costa Rica & 158 \\
\hline Total study area (ha) & N/A & N/A & 200 & No allocation \\
\hline Land use change & $\begin{array}{c}\text { No land use } \\
\text { change }\end{array}$ & N/A & $\begin{array}{c}\text { No land use } \\
\text { change }\end{array}$ & $\begin{array}{c}\text { Not included due to lack of information } \\
\text { before 20 years of cultivation }\end{array}$ \\
\hline Allocation & $\begin{array}{c}\text { No } \\
\text { allocation }\end{array}$ & N/A & $\begin{array}{c}\text { Economic } \\
\text { allocation }\end{array}$ & $58-79$ \\
\hline Total CF (kgCO 2 eq/kg of fresh pineapple) & 0.23 & 0.26 & 0.16 & 0.17 \\
\hline
\end{tabular}

*only $\mathrm{N}_{2} \mathrm{O}$ emission

that overall GHG emissions would be decreased if farmers used fertilizer, complying with what is suggested by GAP. This is because $70 \%$ of the farmers in this study used too much of the fertilizer than the plants needed. Moreover, yield is another factor contributing to CF. Although yield in this study is higher than the average in Thailand of around $24,250 \mathrm{~kg} / \mathrm{ha}$ in 2013 , it is still lower than in other countries like Costa Rica, of which yield was around $59,719 \mathrm{~kg} / \mathrm{ha}$, or Columbia's yield at around $44,650 \mathrm{~kg} / \mathrm{ha}$ in the same year [15]. Thus, productivity per cultivation area should be enhanced in order to mitigate the unit environmental load.

Associated with canned pineapple production, which poses a CF contribution at $84.1 \%$ per one canned pineapple (Table 7), the main contributors are packaging (tin cans), fuel for steam production, sugar, and methane from a wastewater treatment plant. In the acquisition of raw materials such as sugar, it must be taken into account that some farmers burn sugarcane in order to reduce harvest cost, causing GHG emissions at around $552.5 \mathrm{~kg}$ $\mathrm{CO}_{2}$ eq/ha•y [30]. For this reason, CF can also be reduced if the factory chooses to acquire sugar from farmers who do not burn their crops for harvesting. The other factors include: 1) coal management prior to being used in a boiler, 2) change of fuel such as replacing steam with biomass, 3 ) the use of methane from wastewater treatment, and 4) increased use of recycled cans.

Coal management prior to being used in a boiler. This factor should be considered because the factory uses coal for steam production. Before use, coal is kept in an outdoor area without any protection from the rain. This can cause high humidity in the coal, which consequently causes an increased use of coal in the process more than originally necessary. Humidity can be avoided and reduced by stopping watering of the coal and keeping it in a dry indoor area with rain protection. Statistically, coal consumption is $1,262 \mathrm{~kg} /$ hour and the humidity is around $0.15 \mathrm{~kg}$ humidity $/ \mathrm{kg}$ coal. Once humidity is controlled to $0.10 \mathrm{~kg}$ humidity $/ \mathrm{kg}$ coal, $132 \mathrm{~kg}$ of coal can be reduced per hour. This is elaborated upon in scenario 4.

Use of biomass in steam production. Nowadays, biomass is more widely used in steam production. The heat of biomass (considered in terms of saw dust)

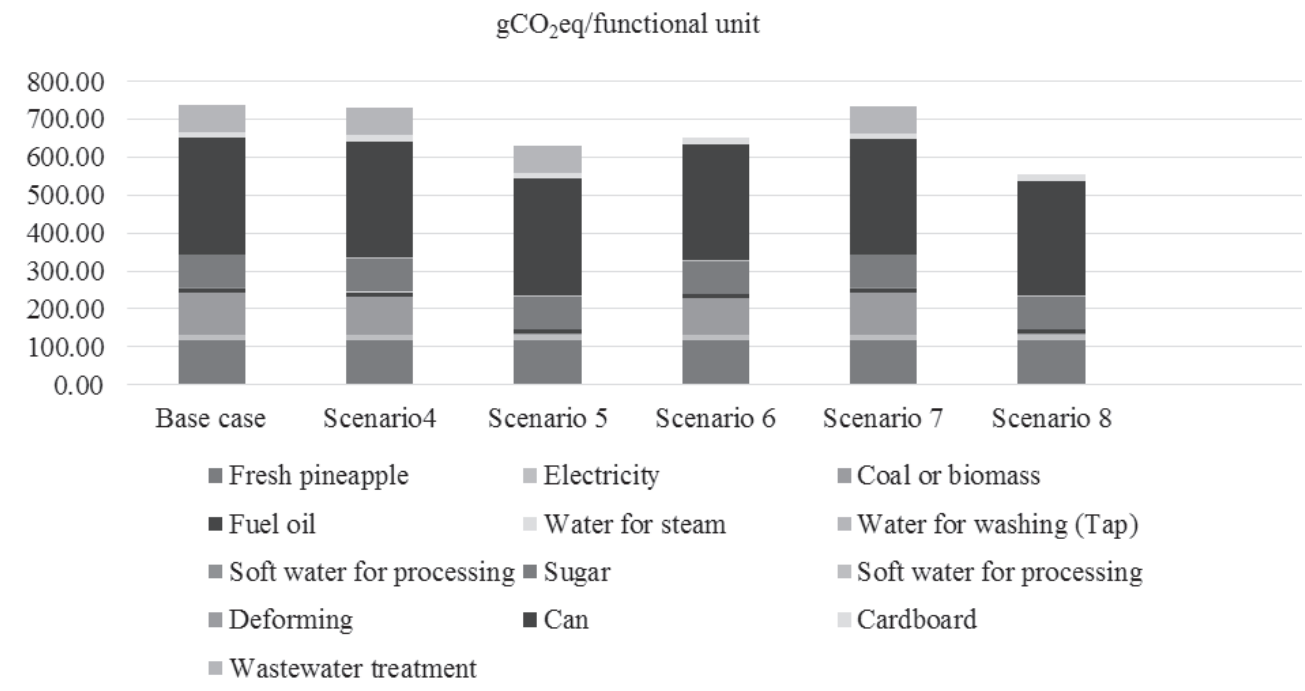

Fig. 3. CF of canned pineapple opportunity GHG reduction scenarios. 
is $10.32 \mathrm{MJ} / \mathrm{kg}$, while the heat of imported coal is $26.37 \mathrm{MJ} / \mathrm{kg}$. As a result, around 2.56 times more saw dust is needed than the amount of coal to maintain the same level of heat. This is set as scenario 5 .

Use of methane from wastewater treatment. Wastewater from the factory can be utilized to produce biogas for use as fuel in the factory itself as this fruit waste consists of high moisture content and a high level of carbon. Biogas production from this waste is an effective solution for waste management. The heat of biogas is $20.93 \mathrm{MJ} / \mathrm{m}^{3}$. This is regarded as scenario 6 .

Increased use of recycled cans. Recycled packaging such as steel, aluminium, or tin cans not only allows for the conservation of virgin materials but also saves energy. In addition, it will reduce GHG. However, there have been no results for tin can recycling or its correlation to $\mathrm{GHG}$ reduction reverted so far. Recycling rates of municipal solid waste (MSW) for aluminium and metal in the studied area were $0.51 \%$ and $3.61 \%$, respectively [31]. Based on this information, it can be assumed that implementing $2 \%$ recycled packaging can potentially reduce $\mathrm{GHG}$ emissions by $1.4 \%$. This is set as scenario 7 .

Fig. 3 shows $\mathrm{CF}$ of canned pineapple per functional unit in scenarios 4-7 compared with the base case. Scenario 8 is the assumption when scenarios 5-7 are all put into practice simultaneously. It is found that biomass can reduce $\mathrm{GHG}$ emissions by $14.7 \%$. Biogas can mitigate GHG emissions by $11.6 \%$, and coal humidity reduction can reduce emissions by $1.2 \%$. Finally, package recycling $(0.6 \%)$ resulted in $1.4 \%$ fewer emissions. The feasible methods from scenarios 5-7 can potentially reduce GHG emissions by $24.8 \%$ combined. The highest contribution is still tin cans, which cause $41 \%$ to $55 \%$ contribution. The higher the recycle rate that can be encouraged, the more $\mathrm{CF}$ of the product that can be reduced.

\section{Conclusion}

This study assessed the CF of pineapple cultivation and canned pineapple production within specified research areas in central Thailand. Data was obtained from questionnaires and manufacturing information provided by the factory. Information about cultivation was acquired from 25 participating farmers operating small-, medium-, and large-sized farms. In terms of canned pineapple production, data was collected from one manufacturing plant. The average $\mathrm{CF}$ from cultivation of fresh pineapples was $172 \mathrm{~g} \mathrm{CO} e q / \mathrm{kg}$, while that of canned pineapple production was $738 \mathrm{~g} \mathrm{CO}_{2} \mathrm{eq} / \mathrm{can}$. The main contribution of GHG emissions during the cultivation period was fertilizer, accounting for $58-79 \%$. However, the size of the farm was a crucial variable in our calculations. $\mathrm{CF}$ was less of a variable for a large farm than it is for a smaller one. Incidentally, burning pineapple residue caused only a slight effect on CF. Concerning canned pineapple production, the main contribution was the can and packaging, which accounted for almost $42 \%$. Opportunities available to reduce GHG emissions include replacing coal with biomass in steam production, the use of biogas from wastewater treatment, and increasing the recycle rate of tin cans to decrease the use of virgin materials. In this study, it was also found that GHG emissions from canned pineapple production could be reduced by more than $15 \%$ when biomass was introduced for use as fuel. In addition, GHG emissions can be mitigated by $12 \%$ when biogas is utilized. However, effectively mitigating GHG emission means that strategy must be planned, starting from the cultivation process. For example, farmers should be educated about appropriate pineapple cultivating methods, encouraged to use fertilizers suitably in accordance with suggestions from GAP, and guided to find opportunities to increase yields. However, this study did not consider the case of forest encroachment, which causes changes in emissions due to land use change - an issue that is still widely debated. Therefore, future research involving cultivation should take this issue into account as well. Additional environmental impact from seedling and nursery period, usually excluded from life cycle assessment, should be anticipated for data integrity.

\section{References}

1. REGMI A., MEADE B. Demand side drivers of global food security. Glob Food Sec. 2, 166, 2013.

2. LOEHR R.C., Pollution control for agriculture, Academic Press Inc. New York, 1977.

3. EDENHOFER O., PICHS-MADRUGA R., SOKONA Y., FARAHANI E., KADNER S., SEYBOTH K., ADLER A., BAUM I., BRUNNER S., EICKEMEIER P., KRIEMANN B., SAVOLAINEN J., SCHLOMER S., VON STECHOW C., ZWICKEL T. IPCC 2014 Climate change 2014: mitigation of climate change. In Minx JC (editor). Contribution of Working Group III to the Fifth Assessment Report of the Intergovernmental Panel on Climate Change, Cambridge University Press, Cambridge, United Kingdom and New York, USA, 2014.

4. ICAP (International Carbon Action Partnership), ETS Detailed Information Thailand, Available online: https:// icapcarbonaction.com/en/?option $=$ com_etsmap\&task $=\mathrm{e}$ xport \& format $=$ pdf\&layout $=1$ ist $\&$ systems $\% 5 B \% 5 \mathrm{D}=81$., (accessed on 16 October 2016), 2012.

5. ADEWALE C., HIGGINS S., GRANATSTEIN D., STOCKLE C.O., CARLSON B.R., ZAHER U.E., CARPENTER-BOGGS L. Identifying hotspots in the carbon footprint of a small scale organic vegetable farm. Agric Syst. 149, 112, 2016

6. MOHAMMADI A., RAFIEE S., JAFARI A., KEYHANI A., DALGAAD T., KNUDSEN M.T., NGUYEN T.L.T., BOREK R., HERMANSEN J.E. Joint life cycle assessment and data envelopment analysis for the benchmarking of environmental impacts in rice paddy production. J Clean Prod. 106, 521, 2015.

7. TORRES C.M., ANTON A., FERRER F., CASTELLS F., Greenhouse gas calculator at farm level address to the growers. Int J Life Cycle Assess., Available online: http:// link.springer.com/article/10.1007/s11367-016-1068-Y, 2016.

8. PANDEY D., AGRAWAL M., Carbon footprint estimation in the agriculture sector. In Muthu SS. ed. Assessment of 
carbon footprint in different industrial sectors. Springer, 25, 2014.

9. CORDES H., IRIARTE A., VILLALOBOS P. Evaluating the carbon footprint of Chilean organic blueberry production. Int J Life Cycle Assess. 21, 281, 2016.

10. WROBEL-JEDRZEJEWSKA M., STEPLEWSKA U., KULETA P., PRZYBYSZ L., POLAK E. Carbon footprint of fruit paste technology. Pol J Environ Stud. 25 (1), 341, 2016.

11. PLAWECKI R., PIRONG R., MONTRI A., HAMM M.W. Comparative carbon footprint assessment of winter lettuce production in two climatic zones for Midwestern market. Renew Agr Food Syst. 29, 310, 2014.

12. INGWERSEN W.W. Life cycle assessment of fresh pineapple from Costa Rica. J Clean Prod. 35, 152, 2012.

13. WAFF (West Africa Fair Fruit), Summary of studies on environmental performance of fresh pineapple produced in Ghana for export to Europe, 2011, Available online: http://www.twinn.com.au/pdf/C-footprint-of-pineappleproduction-and-transport-WAFF.pdf., (accessed on 07 November 2016), 2011.

14. BRENTON P., EDWARDS-JONES G., JENSEN M.F., Carbon Footprints and Food Systems, Do Current Accounting Methodologies Disadvantage Developing Countries?, The World Bank. Washington D.C., 2010.

15. FAOSTAT, Food and Agriculture Organization of the United Nations, Statistic Division, Available online: http://www. fao.org/faostat/en/\#data, (accessed on 04 October 2016), 2016.

16. ISO14067, Greenhouse gases-carbon footprint of products-requirements and guidelines for quantification and communication, International Organization for Standardization. Geneva. Switzerland, 2013.

17. ISO14040, Environmental Management-Life Cycle Assessment e Principles and Framework, International Organization of Standardization. Geneva. Switzerland, 2006.

18. ISO14044, Environmental management-life cycle assessment-requirements and guidelines, International Organization for Standards, Geneva, Switzerland, 2006.

19. VINYES E., GASOL C.M., ASIN L., ALEGRE S., MUNOZ P. Life cycle assessment of multiyear peach production. J Clean Prod. 104, 68, 2015.

20. OAE (Office of Agricultural Economics), Agricultural statistics of Thailand 2010, Available online: http://www. oae.go.th/download/download journal/yearbook53.pdf., (accessed on 15 October 2016), 2010.

21. IPCC. Intergovernmental Panel on Climate Change, IPCC Guidelines for National Greenhouse Gas Inventories, 2006.

22. AKHTAR S., SHAKEEL S., MEHMOOD A., HAMID A., SAIF S. Comparative analysis of animal manure for soil conditioning. Intl J Agron Plant Prod. 4, 3360, 2013.

23. ECOINVENT CENTRE. Ecoinvent database Ver.2.2. categories for processes, Ecoinvent Centre, Swiss Centre for Life Cycle Inventories, Zurich, Switzerland, 2010.

24. MTEC, Thai national life cycle inventory database, National Metal and Materials Technology Center, National Science and Technology Development Agency of Thailand, 2014.

25. DIW (Department of Industrial Works), Industrial sector codes of practice for pollution prevention (Cleaner Technology): Canned fruit and vegetables (pineapples) industry, Available online: http://php.diw.go.th/ctu/files/ pdf/codeofpractice_cannedfood th.pdf., (accessed on 04 November 2016), $\mathbf{2 0 0 2}$.

26. AHMED O.H., HUSNI M.H.A., ANUAR A.R., HANAFI M.M. Towards sustainable use of potassium in pineapple waste. Sci World J. 4, 1007, 2004.

27. PRACHYALAK P., CHAVALIT M., KARNVIBOON P., Using stems and leaves of pineapple with fresh grass as basal feed for lactating cows. Annual Research Report year 1999. Bureau of Animal Nutrition Development, Department of Livestock Development. Available online: http://nutrition. dld.go.th/Research\%20Report53-55/Research_Knowlage/ RESEARCH/research_full/2542/R4212.pdf., (accessed on 04 November 2016), 1999.

28. ANDREAE M.O., MERLET P., Emission of trace gases and aerosols from biomass burning. Glob Change Biogeochem Cy. 15, 955, 2001.

29. DOA (Department of Agriculture), Good Agricultural Practices (GAP) for pineapple, 2007, Available online: http://gap.doae.go.th/toon/4/gap.html., (accessed on 11 October 2016), 2007.

30. YUTTITHAM M., GHEEWALA S.H., CHIDTHAISONG A. Carbon footprint of sugar produced from sugarcane in eastern Thailand. J Clean Prod. 19, 2119, 2011.

31. CHALLCHAROENWATTANA A., PHARINO C. Co-benefits of household waste recycling for local community's sustainable waste management in Thailand, Sustainability. 7, 7417, 2015. 